\title{
Volunteer Tourism as A Factor of Sustainable Development
}

\author{
Galenko Elena Vasilyevna $^{1, *}$, Ovcharenko Natalia Petrovna ${ }^{2}$ and Orlovskaya Iuliia Viktorovna ${ }^{3}$ \\ ${ }^{1}$ Federal State Autonomous \\ Educational Institution for Higher Education \\ «Far Eastern Federal University » (FEFU), \\ School of economics and management, \\ (Vladivostok, Russia.) \\ ${ }^{2}$ Federal State Autonomous \\ Educational Institution for Higher Education \\ Education «Far Eastern Federal University » (FEFU), \\ School of economics and management, \\ (Vladivostok Russia) \\ ${ }^{3}$ Federal State Autonomous \\ Educational Institution for Higher Education \\ Education «Far Eastern Federal University » (FEFU), \\ School of economics and management, \\ (Vladivostok Russia) \\ ${ }^{*}$ Corresponding author's email: galenko_tgey [AT] mail.ru
}

\begin{abstract}
The article studies the problem of the volunteer tourism development as an important part of the concept of sustainable tourism. Approaches to the assessment of volunteer tourism and sustainable tourism development proposed by various international organizations (UNWTO, the Worldwide Council for Sustainable Tourism, the European Environment Agency, the European Commission) and scientists. The author substantiates the importance of forming the system of the sustainable development of tourism indicators, enriched with the concept of volunteer tourism and the need for continuous monitoring at different levels. It is concluded that volunteer tourism, directly manifested in the context of the development of each country, is considered by a number of international organizations, foreign and domestic researchers as a factor of sustainable tourism development. In the article, the hypothesis of a direct positive relationship between sustainable tourism development and volunteer tourism (volunteer tourists) is verified on the basis of a questionnaire survey of volunteer tourists. The proposed approaches to the assessment of the sustainable tourism development enriched with the concept of volunteer tourism cannot be considered universal, since each country needs its own system.
\end{abstract}

Keywords - volunteer tourism, steady tourism, tourists-volunteer

\section{INTRODUCTION}

In the modern world, volunteer tourism is a new phenomenon of the XXI century, which is able to unite volunteers from all countries to participate in volunteer projects. The development of sphere of volunteer tourism is growing rapidly, involving new like-minded people, if according 2008 there were 1.6 million people wishing to participate volunteer tourism in the whole world, according to 2017 data, 4 million people took part in volunteer tourism in the Russian Federation [1]. Today in France-19\%, in Germany -34\%, in the United States-up to 50\% of the population involved in volunteer projects and programs. Such a high popularity of volunteering is associated with a great «experience» of the volunteer movement and state support in Western countries. In Russia, volunteering is mainly based on the activities of non-profit organizations, and only in recent years the state noticed that in the USA, Japan and other countries the volunteer movement is not only supported, but often organized by the state [2].

The level of awareness and interest of participation in some form of voluntary travel among tourists is increasing, besides a wide range of volunteer projects and excursions are presented in the world practice. Volunteer tourists are invited to participate in the construction of schools, houses and boarding schools in developing countries, lions-care in South Africa, elephants-care in Thailand or sea turtles-care in Costa Rica, conducting environmental or social research, helping to preserve the environment, teaching English to children, etc. These areas involve the identification and integration of certain areas of volunteer tourism in the following groups: 
- Social volunteer tourism (education of children, construction of socially important facilities, assistance in the restoration of destroyed areas after natural disasters, humanitarian assistance, etc.);

- Environmental volunteer tourism (assistance in nature reserves, animal care, cleaning of wild beaches and territories, construction of ecological trails, etc.);

- Scientific volunteer tourism (assistance in archaeological excavations, participation in various focus groups, expeditions, studying the life and customs of local residents, etc.);

- Event volunteer tourism (assistance in holding international forums, various competitions, sports competitions, etc.).

The approach of the volunteer tourism development is closely intertwined with sustainable tourism, as discussed in «Agenda of XXI century for the Travel and Tourism industry: towards environmentally sustainable development», compiled by the world tourism organization, the world travel and tourism Council and the Earth Council in the 1995.The document is based on 12 principles, which reflect the issues of socio-economic and environmental orientation, namely: the development of tourism oriented at supporting the identity, culture and interests of indigenous peoples, employment of local population, planning of tourism development with the participation of the local community, etc. [3-4]. It should be noted that numerous works on sustainable tourism development are mainly devoted to the study of its contribution to the sustainable territories functioning of the host countries, which is generally impossible without tourist volunteers, as well as building close partnerships between the tourism industries, authorities at all levels, local communities and tourists.

At the same time, none of the works pays due attention to tourists-volunteers, as an example of education of modern youth, the priority direction of development of voluntary assistance or the alleviation of material poverty of some groups in society, work in reserves and national parks, restoration and preservation of the environment.

Today, the solution to this problem is hampered by the following contradictions:

- The increasing role of the volunteer tourist in the social development of society and lack of the development of its theoretical foundations;

- The lack of data on the work of volunteer tourism and the criteria for assessing their contribution to the sustainable tourism development;

- From year to year the growing need for voluntary assistance and the lack of advertising and other information available to the wide audience.

The lack of the sufficient number of works on this issue and the revealed contradictions determined the purpose of this publication - to study the development of volunteer tourism as an important part of the concept of sustainable tourism and to study the attitude of volunteer tourists to this phenomenon.

The main hypothesis of the study is there is a direct (positive) relationship between the sustainable tourism development and volunteer tourism (volunteer tourists).

Since the problems of the volunteer tourism development as an important part of the concept of sustainable tourism differ significantly across countries, as well as economic, social and environmental factors have significant and divergent territorial differences, their direct comparison is very difficult. In addition, the tourism development in each country is seen as a tool for their sustainable development through various government programs and strategies. According to author's the results obtained will serve as a basis for deepening the ideas of modern researchers about the relationship between the two phenomena under consideration; will allow to take them into account in the development of new strategies, programs for the development of volunteer tourism and recreation in the context of sustainable development of the country; can be used in the formation of a list of indicators of socio-economic efficiency of the functioning of the sphere of recreation and volunteer tourism, to improve the planning and management of new volunteer projects and programs of tourist destinations and countries. It seems that the relationship between volunteer tourism and sustainable development of recreation and tourism, it is advisable to explore through a similar method, the relevant indicators and conduct a questionnaire survey of volunteer tourists.

Taking into account that persons of any age are involved in voluntary tourist activity to participate in volunteer projects of tourist orientation in different countries of the world, we can say that this type of tourism contributes not only to the personal growth and satisfaction of each traveler, but also to the development of the host community. Some authors argue that volunteer tourism has been conceptualized as a form of alternative experience that allows a tourist to go beyond simply visiting a place or «passing through a place as a bystander». Instead, the tourist-volunteer lives «inside» and brings a positive contribution to the community, gets experience in accordance with the belief in the concept of «mutual benefit». In this interpretation, the concept of «tourist-volunteer» has the following definition - it is a person, a volunteer who voluntarily agreed to help the society free of charge, to be responsible for the fulfillment of their obligations, combining voluntary work with the classic elements of travel and tourism - ecology, sports, language 
learning, culture, geography, history, etc. [5].

Other authors define volunteer tourism as a form of tourism, when tourists-volunteer to partially invest in the journey, where they worked voluntarily in organized projects, including assisting the company through the distribution of basic necessities and other resources, the restoration and preservation of the environment, as well as assistance in conducting field research. Kruglova M. S. gives the following definition of the concept of «volunteer tourism»-it is the practice of travelling tourists under temporary work programs in the territory where various organizations require the work of volunteers [6].

In such a way, the volunteer tourism can be considered as a popular form of international travel, which allows each volunteer to make an individual contribution to the sustainable development of tourism in the host country.

Volunteers consider their activities as a tool for social, cultural, economic and environmental development. The World Declaration of Volunteerism emphasizes that volunteerism is a voluntary choice that reflects personal views and positions, active participation of the citizen in the life of human communities. It should contribute to the improvement the quality of life, personal prosperity and human solidarity. The joint activity of volunteers is carried out, as a rule, within the framework of various associations, contributes to the realization of basic human needs on the way of building a more just and peaceful society, more balanced economic and social development, creation of new jobs and new professions [7].

It is worth noting that in 2015 at The United Nations summit on sustainable development, it was announced that volunteers will become an integral part of the efforts to achieve the 17 Global sustainable development goals aimed at eradicating poverty, combating inequality, injustice and combating climate change by 2030 . The sustainability in tourism is achieved through a positive balance of environmental, socio-cultural and economic aspects of the tourism industry, necessary to ensure favorable working conditions, the life of the local population of the destination and the preservation of their natural environment [8-9].

In Agenda of the 21 century for the Travel and Tourism industry: towards environmentally sustainable development states that «Sustainable tourism development meets the current needs of tourists and host regions, protecting and enhancing opportunities for the future. All resources should be managed in a way that meets economic, social and aesthetic needs, preserves cultural integrity, important environmental processes, and biological diversity and life support systems. The sustainable tourism products are products that exist in harmony with the local environment, society, culture in a way that benefits rather than harms tourism development» [10-11].

Maksarova E. M. defined sustainable tourism development as a long-term-oriented tourism development, which achieves a balance in the implementation of economic, environmental, social and cultural development goals, taking into account the interests of all stakeholders (tourists, destination and directing destinations, local population) [12].

\section{METHODOLOGY}

According to the World Tourism Organization, the causal link between tourism and the overall level of sustainable development is less evident, especially with regard to environmental integrity. In recent years, the tourism industry accounts for 5\% of global $\mathrm{CO}_{2}$ emissions and needs to address energy consumption, food waste and waste management in general. This approach contributed to the development of global criteria for sustainable tourism as part of a broad initiative managed by the Partnership of International Organizations [13].

With regard to the current economic realities, tourism worldwide has the great importance as a source of income and a source of jobs; however, the development of tourism is impossible without interaction with the environment. Taking into account the environmental component and managing tourism development on its basis will reduce the possible negative impact. This approach determined the tendency of transition from the study of General principles to the development of practical recommendations for the implementation of sustainable tourism development programs in various destinations. The development of indicators of sustainable tourism development necessary for tourism planning and management at different levels was recognized as a major challenge. The studied and selected basic and indicative set of additional indicators allows you to adapt the system of tourist indicators (The European Tourism Indicator System, ETIS) to a specific area with its features. Many authors offer their classification of indicators of the sustainable tourism development: the Economic; The ecological block; The social bloc; The block of an estimation of quality of given services $[14,15,16]$.

Applying the method of analogy for the implementation of a new paradigm of sustainable tourism development in the XXI century enriched by the concept of volunteer tourism, the authors propose to create a system of indicators of sustainable tourism development on the basis of criteria determining the achievement of certain goals and improving the living standards of the population as a result of tourism activities. Speaking about the indicators of sustainable development, enriched with the concept of volunteer tourism, we can distinguish two methodological approaches: 
1. It is based on the construction of an indicators system, each of which reflects certain aspects of sustainable development of the country, including economic, environmental, social, volunteer, and institutional.

2. It involves the construction of an aggregated (integral) indicator based on which can be judged on the degree of sustainability of socio-economic development, taking into account the participation of volunteer tourists.

Indicators should be measurable, relevant, accessible, reliable, consistent with the specific conditions and objectives of sustainable tourism development, as well as be compatible with the recommendations that are used in the world practice.

\section{RESULT AND DISCUSSION}

It should be noted that indicators of target programs aimed at the development of recreation and tourism in many countries, including Russia, the number of volunteer tourists who took part in environmental, social, cultural or other projects are not provided, so the authors propose to include such indicators, an example is presented in table 1.

Table 1: Indicators of sustainable tourism development enriched with the concept of volunteer tourism

\begin{tabular}{|c|c|}
\hline Programs & Indicators \\
\hline \multirow{11}{*}{$\begin{array}{l}\text { The Federal target program } \\
\text { "Development of domestic and inbound } \\
\text { tourism in the Russian Federation } \\
\text { (2011-2018): approved. resolution of the } \\
\text { Government of the Russian Federation } \\
\text { dated } 2 \text { Aug. } 2011 \text { № } 644\end{array}$} & Number of Russian citizens placed in collective accommodation facilities \\
\hline & The number of foreign nationals placed in collective accommodation facilities \\
\hline & $\begin{array}{c}\text { The installation area of the hotel room capacity in the collective accommodation } \\
\text { facilities }\end{array}$ \\
\hline & $\begin{array}{c}\text { Investments in fixed capital of accommodation facilities (hotels, places for temporary } \\
\text { residence) }\end{array}$ \\
\hline & Number of beds in collective accommodation facilities \\
\hline & Number of persons working in collective accommodation facilities \\
\hline & Number of persons working in travel agencies \\
\hline & The volume of paid tourist services provided to the population \\
\hline & The volume of paid hotel services and similar accommodation facilities \\
\hline & Number of volunteers-tourists who took part in programs or projects \\
\hline & The volume of work performed by volunteers-tourists \\
\hline \multirow{6}{*}{$\begin{array}{l}\text { State program of the Russian Federation } \\
\text { "Development of Culture and Tourism" } \\
\text { for } 2013-2020 \text { approved. Resolution of } \\
\text { the Government of the Russian } \\
\text { Federation of } 15 \text { April. } 2014 \text { No. } 317\end{array}$} & Level of satisfaction with the quality of provided services \\
\hline & $\begin{array}{l}\text { The volume of paid services provided to the population in the field of domestic and } \\
\text { inbound tourism (including services of travel agencies, hotels and similar } \\
\text { accommodation) }\end{array}$ \\
\hline & $\begin{array}{c}\text { Number of accommodation facilities classified in accordance with the classification } \\
\text { system of hotels and other accommodation facilities }\end{array}$ \\
\hline & $\begin{array}{l}\text { Number of foreign citizens of the Russian Federation placed in collective } \\
\text { accommodation }\end{array}$ \\
\hline & $\begin{array}{l}\text { Number of volunteers-tourists who took part in the programs for the protection of } \\
\text { landscape and biodiversity }\end{array}$ \\
\hline & $\begin{array}{l}\text { The number of volunteers-tourists who took part in the programs for the protection } \\
\text { and strengthening of local national and cultural specificity and assets }\end{array}$ \\
\hline
\end{tabular}

The indicators of sustainable tourism development, enriched with the concept of volunteer tourism, presented in the table, partially reflect the list of sustainable and volunteer tourism. The formation of indicators system should include the stages of preparatory work, development, implementation, improvement. At the first preparatory stage it is necessary to define strategic and tactical goals of sustainable tourism development, enriched with the concept of volunteer tourism. At the stage of development, it is necessary to select indicators that are acceptable for evaluation and group them into areas (economic, social and environmental development, taking into account volunteer tourism). Selected key indicators should display the most important information for the assessment of sustainable tourism development, enriched with the concept of volunteer tourism. In the following stages, the implementation, error detection, improvement of the developed system and elimination of defects. The system of indicators should provide constant monitoring of the tourism sustainability and the development of volunteer tourism, while the indicators themselves are constantly reviewed and updated.

Discussing the identified problems, we can say that volunteer tourism covers more and more regions of the world and spheres of life of the world community, being an important part of the concept of sustainable tourism development and corresponding to the concept of "meeting the needs of the present, without compromising the ability of future generations to meet their needs." In the study, it was determined that currently, there are three aspects of sustainable development: a) social; б) environmental; в) economical. For this reason, within the framework of this study it was expedient to identify how directly people engaged in volunteer tourism evaluate the contribution of this phenomenon to the aspects of sustainable development for the territories. The venue for the XXIII Olympic Winter games and XII Paralympic winter 
games 2018 in Pyeongchang-gun, South Korea carried out social research aimed at assessing the impact of volunteer tourism on the sustainable development of territories. This study was conducted in the form of a questionnaire. The sociological survey was conducted in two languages: Korean and English. The questionnaire in the Korean version was answered exclusively by representatives of South Korea. The questionnaire in English was answered by representatives of different countries, which were directly related to these events and volunteer activities. The survey was conducted using the Internet resource survio.com, where the electronic questionnaire was developed. The questionnaire was distributed through social networks, as well as personally when using mobile devices. 72 respondents were interviewed. The respondents are volunteers who help in holding the Olympic and Paralympic games in Pyeongchang in 2018. The survey involved 72 respondents from 14 countries, 26 male and 46 female, of different age groups in the range up to 18 years and more than 55 years. Among the participants of the questionnaire are students, workers, pensioners, the unemployed. The aim of the study was to identify the attitude of volunteers-tourists to determine the impact of volunteer tourism on sustainable development of territories. To carry out this study, respondents were asked to assess on a scale of 1 to 5 the impact of volunteer tourism on each aspect of sustainable development: social, environmental and economic, where 1 - does not have a significant impact, and 5 - has a very significant impact. The data obtained are shown in table 2 .

Table 1: Assessment of the impact of volunteer tourism on sustainable development

\begin{tabular}{c|c|c|c|c|c|c}
\hline & $\mathbf{1}$ mark & $\mathbf{2}$ mark & $\mathbf{3}$ mark & 4 mark & 5 mark & $\begin{array}{c}\text { Average } \\
\text { mark }\end{array}$ \\
\hline Social aspect & $3(4,2 \%)$ & $1(1,3 \%)$ & $15(20,8 \%)$ & $25(34,7 \%)$ & $29(40,2 \%)$ & 4,1 \\
\hline Environmental aspect & $2(2,7 \%)$ & $6(8,3 \%)$ & $21(29,1 \%)$ & $24(33,3 \%)$ & $19(26,3 \%)$ & 3,75 \\
\hline Economical aspect & $2(2,7 \%)$ & $7(9,7 \%)$ & $16(22,2 \%)$ & $31(43 \%)$ & $16(22,2 \%)$ & 3,75 \\
\hline
\end{tabular}

As can be seen from the survey results, according to respondents, volunteer tourism affects the social aspect of sustainable development to the greatest extent. Almost $75 \%$ of respondents rated the degree of its influence on "4" and "5" points. In such a way, the majority of those who voted positively assessed the impact of volunteer tourism on all aspects of sustainable development of territories, and the average score of the impact of volunteer tourism on sustainable development of territories is "3.9" on a five-point scale from "does not influence" to "has a very significant impact". The obtained figure shows that the development of volunteer tourism leads to significant positive changes for the sustainable development of the territories.

\section{CONCLUSION}

Summarizing the foreign experience of the organization of volunteer tourism as a form of sustainable tourism, we see that volunteer tourism helps all aspects of sustainable development. All studied approaches to the consideration of volunteer tourism are united by the idea of making trips with volunteer goals and voluntary assistance in the development of certain aspects in the destination. The emphasis is on the fact that the development of volunteer tourism helps to improve society as a whole. Regardless of the approach to the definition of volunteer tourism, all the authors highlight the fact of its favorable impact on the environmental, social or economic aspects of the region receiving tourists. These aspects are an integral characteristic of sustainable development; the authors have made an attempt to prove the impact of volunteer tourism on sustainable tourism. It was found that volunteer tourism has a positive impact on the life of the host communities, the local population of the territories where volunteers are sent: help the local population of the lagging regions to improve the quality of life, provide support and lays the foundation for their further development. Taking part in volunteer tourism, volunteers contribute to the local economy, supporting local entrepreneurs. The participation of volunteers in volunteer tourism triggers a "wave effect". By their example, volunteers inspire the local population to develop, take an active life position and help others, which will be passed on to the next generations, contribute to positive changes in the life of the lagging territories and their inhabitants, and thus we can say with confidence that the development of volunteer tourism will contribute to the sustainability of tourism.

At the same time, our research showed that this area of scientific research and practice does not involve unambiguous answers, results and management decisions. The development of the directions of development of volunteer tourism as an important part of the concept of sustainable tourism requires an individual approach, taking into account the specifics of the country. It is also advisable to further study the nature of the relationship of sustainable tourism development, enriched with the concept of volunteer tourism.

\section{REFERENCES}

[1] Galenko E. V., Kremenetskaya A. M. Need and trust as tools to support the development of volunteer tourism. Collection of the $\mathrm{V}$ International scientific and practical conference: Modern hotel and restaurant business: Economics and management, pp. 164-167, 2018. 
[2] Bozhko L. DCultural consequences of globalization:" new nomads "and" new identities". Scientific statements. Series History. Political science. Economy. Informatics, vol. 22 (165), pp. 73 - 78, 2013.

[3] Loktionova, TA The history of the emergence and formation of volunteering in Russia, Young Scientist. vol. 8, pp. 267-269, 2012.

[4] Nezdoyminov S. G. Ecologization of tourism as a factor of sustainable development, Regional study, vol. 1(43), pp. 133-139, 2014.

[5] Pirogov O. V., Pirogova A. Yu. The role of sustainable tourism in the world. International journal of applied and fundamental research, vol. 7, pp. $305-309,2017$.

[6] Raymond E.M., Hall C.M. The development of cross-cultural (mis)understanding through volunteer tourism, Journal of Sustainable Tourism, vol. 16 (5), pp. 530-543, 2008.

[7] McGehee N.G, Andereck, K.L. Factors predicting rural residents' support of tourism, Journal of Travel Research, vol. 43 (2), pp. 131, 2004.

[8] McGehee N.G. Oppression emancipation, and volunteer tourism: Research Propositions, Annals of tourism research, vol. 39 (1), pp. 84-107, 2012.

[9] Kiseleva T. G. Study of the dominant motivation to participate in volunteering, Yaroslavl Pedagogical Gazette, vol. 2 (2), pp. 44-48, 2013.

[10] Galenko E. V., Kremenetskaya A. M. Volunteer tourism as a factor of sustainable development. Eurasian international economic scientific and practical conference, pp. $126-130,2018$.

[11] Kruglova M. S. The phenomenon of volunteering in the modern theory and practice of tourism. Postgraduate, vol. 5 1 (10), pp. $77-80,2015$.

[12] Chistochina A. V., Dumler A. A., Vikulova I. L. Organization and implementation of volunteer activities. (Educational and methodical manual. Krasnoyarsk. SFU), pp. 140, 2013.

[13] Kavros A. I. On the issue of sustainable tourism. The works of BGTU, vol. 7, pp. 320 - 325, 2016.

[14] Penkin N. V., Shakhova O. Approaches to assessing sustainability of tourism in the region. Discussion, vol. 10, pp. $38-45,2016$.

[15]Zaliznyak E. A. Indicators of environmental aspects of sustainable development of tourism industry: European experience. Westn. ]. State UN-TA. Ser. 11, Estestv sciences, vol. 1(7), pp. 30-34, 2014.

[16] Seselkin A. I. Sustainable development of tourism as a priority area of the world tourism organization: the formulation of research problems. Bulletin of the RMAT, vol. 1 (10), pp. 9-14, 2014.

[17] Maksarova E. M. The main directions of implementation of the principles of sustainable development in tourism. News of the Russian state pedagogical University. A. I. Herzen, vol. 85, pp. 345-350, 2008.

[18] Galenko E. V., Krivoruchko P. O. The preferences of the tourist when choosing an environmental hotel. The azimuth of scientific research: Economics and management, vol. 2(23), pp.49-52, 2018.

[19] Kiekbaeva E. G. Indicators of sustainable tourism development and their use in Federal programs of tourism development in Russia. News of the Sochi state University, vol. 1 (29), pp. 78-80, 2014.

[20] Grechishkin E. A., Grishina O. A. Indicators for assessing sustainable tourism development. Regional economy. South of Russia, vol. 3 (17), pp. 37-44, 2017.

[21] Rubtsova N. V. Impact of sustainable development of recreation and tourism on sustainable development of the region. News of the Irkutsk state economic Academy, vol. 5 (97), pp. 47-60, 2014. 